\title{
ECOTURISMO E DESENVOLVIMENTO SUSTENTADO
}

\author{
Júlio Serson*
}

\begin{abstract}
RESUMO: A tecnologia e o progresso produtivo, associados às desigualdades regionais e internacionais, provocaram prejuízos ao meio ambiente. Na década de $1970-80$ as sociedades despertaram e partiram em busca de alternativas preservacionistas. da natureza. Este artigo aborda, o turismo sustentado como alternativa para preservação do património natural e ambiental dos países em desenvolvimento e. em especial, o Brasil.
\end{abstract}

UNITERMO: Turismo: turismo sustentado: meio ambiente: ecologia: ecoturismo.

ABSTRACT: The technology and the productive progress, associated to regional and international dissimilarity, caused damage to the enironment. In the 70 and 80 's, the societies awakened and sought presen'ationists alternatives of nature. This article boraches tourism as an altemative for the presen'ation of the natural and ambiental cndowment of developing countries, and specially, Brazil.

KEY WORD: Tourism; sustained tourism; cnviromment; ecology, ecotourism.

\section{A QUESTÃO ECOLÓGICA}

Depois de décadas de desenvolvimento perseguido a todo custo, que derxaram como saldo o progresso produtivo e tecnológico acompanhado de desigualdades internacionais e regionais e prejuízos brutais ao meio ambiente planetário, as sociedades acordaram, nos anos 70-80, para o imperativo de buscar alternativas de crescimento sem os riscos dos danos ecológicos.

(*) Bacharel em Administração pela Fundação Getúlio Vargas de São Paulo: Curso de Especialização em Hotelaria pela Cornell University. Vice-Presid Vila Rica e Presidente da Formatur - Fundação Nacional para a Formação de Recursos Humanos para o Turismo. End. para corresp.: Av. Corifeu de Azevedo Marques. 5677 - 05.3 .39 - São Paulo - SP
- Brasil. 
A Primeira Conferência sobre Meio Ambiente Humano, promo. vida pela ONU, em 1972, em Estocolomo, resultou num document( decisivo para o florescimento da consciência ecológica entre as populaçōes, conhecida por "Nosso Futuro Comum". Desde então, a causa preservacionista vem conquistando, mais do que qualquer outra - con forme é possível constatar nestes tempos de desmantelamento dos regimes socialistas -,fortes contingentes da população mundial.

A Eco-92, a se realizar em junho próximo no Rio de Janciro, certamente renovará o ideário preservacionista, cristalizando a evolução do pensamento ecológico - "o ecologismo é um humanismo" frisa Alain Lipietz - nestas últimas décadas. A contribuição mais inovadora desse pensamento é, sem dúvida a que prevê novo balizamento para ( crescimento industrial e econômico, segundo parâmetros humanita rios que visem a assegurar a sobrevivência do planeta e das geraçōes futuras: a do desenvolvimento sustentado.

O calor dos debates sobre o imperativo de enquadrar o crescimento numa perspectiva de futuro comum concentrou as atençōes mundiais, nestes últimos anos, sobre os países do Hemisfério Sul - que, paradoxalmente, por se encontrarem em estágio inferior de desenvolvi mento, menor taxa de responsabilidade têm pela devastação acarretada pelo processo intensivo de industrialização do Hemisfério Norte, desenvolvido nos últimos dois séculos. E principalmente sobre o Brasil, em função da Amazônia.

As razōes desse interesse são óbvias: a região concentrá, segund () dados da ONU, 33\% das florestas tropicais remanescentes no globo. Estima-se que 1,2 bilhão de toneladas anuais de gás carbônico, mais de $20 \%$ do total mundial, são retirados da atmosfera pelo "pulmão amazônico". Mais: um quinto da água doce que desemboca nos oceanos provêm dos rios que formam a Bacia Amazônica. ${ }^{1}$

Essa condição de foco privilegiado das atençōes mundiais dos movimentos ambientalistas e preservacionistas confere ao Brasil, cm função da Amazônia, a dupla condição de réu e privilegiado. Da competente equação desse paradoxo, veremos a seguir, dependerá em boa parte a alavancagem de um novo ciclo de uma nova frente de desenvolvimento para o País.

\section{ECOTURISMO E DESENVOLVIMENTO SUSTENTADO}

De um lado, somos alvo de uma série de preocupaçōes, acusaçōes e incômodos, parte do qual, convenhamos, injusta. Do outro, entretanto, uma vez que detemos um patrimônio natural e ambiental incontestavelmente inigualável, essa atenção mundial poderá nos ajudar a empurrar para um novo paradigma de desenvolvimento, impulsionado em boa parte pelo turismo ecológico (o ecoturismo), ou "turismo verde".
Essa nova frente turística, aberta, embora ainda não condignamente explorada, não só pela consciência preservacionista ascendente como também pelo esgotamento crescente dos destinos turísticos tradicionais, baseia-se na tendência mundial da busca da convivência harmônica do homem com a natureza.

Dados da Organização Mundial do Turismo dão conta de que, no plano internacional, o turismo é a atividade econômica mais importante - e promissora -, logo após a indústria petrolífera e a indústria bélica. Apenas em 1989, 6,8\% do comércio mundial de bens e serviços foi de responsabilidade das transaçōes turísticas. ${ }^{1}$

Dentre os mercados receptores do turismo internacional, os Estados Unidos ficaram com a parte do leão, naquele ano, abocanhando $34,3 \%$ do fluxo internacional, seguido da França, com $16,5 \%$ e da Espanha, com 16,2\%. Na América Latina, o México foi o país de melhor desempenho, absorvendo $4 \%$ do mercado mundial. Tais números evidentemente não englobam os fluxos turísticos domésticos, calculados dez vezes maior, em média, aos fluxos internacionais.?

Os povos que mais viajam são, naturalmente, os de países com renda nacional mais alta, entre os quais o alemão,o inglês, o norteamericano e o japonês. Sabemos que o governo do Japão vem incentivando as viagens de seus cidadãos, com isto, dinamizando pólos receptivos de vários pontos do globo.

É nesses ricos países emissores que o turismo ecológico emerge como uma alternativa de crescente demanda, em função do esgotamento dos destinos clássicos de viagens.

E aqui indagamos: o que tem feito o Brasil para conquistar esse mercado emissor e para desenvolver o seu potencial de turismo verde? É lamentável constatar que não temos feito nada. Considerado o potencial do País - e não apenas na área de ecoturismo, como também em função de seu patrimônio litorâneo, cultural e histórico -, nossa posição no mercado turístico é irrisória. E, pior, o País vem decrescendo em termos de entrada de turistas internacionais. Em 1989, recebemos 1.402 .897 turistas de outros países², o que representava apenas $0,3 \%$ do total mundial, que aqui geraram uma receita de $1,2 \%$ bilhão de dólares.

Sim, é verdade que a imagem internacional do país se deteriorou nos últimos anos, em função da indefinição quanto à dívida externa, a violência urbana, principalmente a do Rio de Janeiro, ainda a porta de entrada do turista estrangeiro no País, e, "last but not least", a questão ecológica. Esse colapso agravou-se pelo fato de os gastos promocionais do país no exterior terem sido reduzidos quase a zero. Sabemos, também, que os países com políticas de turismo bem sucedidas desenvolvem incessantemente estratégias agressivas de promoção, e nesse rol é possível incluir mercados emergentes como o México, Tailândia, Indonésia e Malásia. 
Acordar para o desafio de estabelecer uma política de turismo competitiva parece ser uma medida acertada, neste ano em que se discute a questão ecológica no Brasil.

É inconstestável que o Brasil se insere no horizonte dos países que melhores resultados podem produzir para a causa ambiental4. Nossa sociedade - e mesmo o governo - vem acordando para a inestimável contribuição que o País pode oferecer a si mesmo e a toda a humanidade no que concerne à preservação ambiental.

\section{CONSIDERAÇÕES FINAIS}

Para que ingressemos numa era de desenvolvimento turístico intensivo e sustentado, o ecoturismo deve ser estimulado e firmemente priorizado, sob a inspiração e a vontade de toda a coletividade. É hora, pois, de governo e sociedade civil se aliarem para poderem atuar com harmonia no que tange a essas potencialidades.

Para isso, é necessário primeiramente fixar eixos turísticos que conservem as características naturais, suas condições ecológicas e ambientais, os padrões culturais dos agrupamentos étnicos e as identidades regionais. É urgente o perfil do turismo brasileiro, privilegiando, com ênfase, o seu potencial ecológico e avaliando corretamente suas possibilidades para nossa balança comercial, para a economia em geral e, insistimos, para a alavancagem de um novo ciclo de desenvolvimento de novo tipo.

Além de representar um filão no qual temos vantagens comparativas potenciais das mais consideráveis, o turismo se insere no rol de alternativas de desenvolvimento sustentado e harmônico com o uso racional de recursos naturais. Por assegurar à humanidade a preservação de seu patrimônio natural e à população em geral melhores condições de vida, o desenvolvimento do ecoturismo pode, inclusive, contribuir para a reversão de nossa imagem externa, hoje maculada.

No momento com que o Brasil passar a convencer os turistas do Primeiro Mundo sobre a política avançada que adota para a preservação ambiental, parte considerável do caminho para a recepção de turistas internacionais estará pavimentada. E com a Eco-92, teremos um cenário de suprema importância para esse convencimento.

A edificação de um meio ambiente melhor deve ser uma das grandes prioridades de um país que realmente almeja ingressar no terceiro milênio sem manchas e na plenitude de suas potencialidades. Multiplicam-se, neste fim de milênio, em escala planetária, as pressões por um melhor modo de vida, pela elevação dos padrões de qualidade da existência. Devemos entender o ecoturismo como uma das respostas a esses anseios.
Nesse contexto, s6 poderão merecer aplausos, internos e externos, iniciativas que visem a estimular o planejamento para o desenvolvimento ,de áreas turísticas que façam do meio ambiente sua principal atraçảo. Que contemplem, em suma, os princípios básicos da harmonia entre o,homem e a natureza.

O ecoturismo é ao mesmo tempo causa e consequência do desenvolvimento sustentado. Ele pode ser a chave para a edificação de um novo País.

\section{REFERENCIAS BIBLIOGRÁFICAS}

1. SERSON, Jálio. Política de turismo e meio ambiente. In: SEMINÁRIO INTERNA. CIONAL DE TURISMO AMAZÔNICO. Manaus, Secretaria de Desenvolvimento Regional da Presidência da Repútlica/OEA/Governo do Estado do Amazonas, nov. 1990

2. EMPRESA BRASILEIRA DE TURISMO. Anuário estatistico da Embratur 9().91. Brasilia, Embratur, 1991

3. HORWATH INTERNATIONAL. 1990 worldwide hotel industry. Horwarth International, New York, 1991, $114 \mathrm{p}$.

4. SERSON, Júlin. Uma indústria da consciência ecológica. Brasilturis Jornal. São Paulo, $2^{2}$ quinz. jan. 1992, p. 13 